\title{
Sugar Composition of Royal Jelly Adulterated with Drone Brood and Bee Honey
}

\author{
Ralitsa Balkanska* \\ Department of Special Branches-Bees, Institute of Animal Science, Kostinbrod, Spirka \\ Pochivka 1, 2232 Kostinbrod, Bulgaria \\ *Corresponding author
}

\section{A B S T R A C T}

\section{Keywords}

Descriptor, Drone Brood (DB), Honey, Royal Jelly (RJ),

Fructose, Glucose, Sucrose

Article Info

Accepted:

17 January 2018

Available Online:

10 February 2018
Royal jelly (RJ) consumption has grown significantly during the last few decades due to its high nutritional value and unique components. The price of pure RJ is much higher than other bee products making it susceptible to adulteration with drone brood (DB) and honey. The aim of the present paper is to characterize the sugar composition of RJ samples adulterated with DB and honey in order to find out possible descriptors for adulterated RJ samples. The information obtained is important for practical purposes in order easily and efficiently to assess the RJ authenticity. This could be useful to detect frauds in RJ samples. The differences in fructose, glucose and sucrose content between RJ and DB samples are significant $(\mathrm{p}<0.001)$. The addition of DB and honey in RJ would change in a certain direction the composition on RJ, mainly with changes of sugar ranges of the samples. The cluster analysis turned out to be useful for finding similarity (or dissimilarity) between pure RJ and mixtures with DB and honey. Parameters such as fructose and glucose can be used as good descriptors for the evaluation of RJ authenticity with honey.

\section{Introduction}

Royal jelly (RJ) is a secretion from the hypopharyngeal and mandibular glands of worker bees (Apis mellifera L.). The composition of RJ is quite complex. It comprises water $(60-70 \%)$, proteins $(9-18 \%)$, carbohydrates (7-18\%), lipids (3-8\%), minerals $(0.8-3 \%)$, vitamins and amino acids (Sabatini et al., 2009; Wytrychowski et al., 2013). RJ is a bee product which is used and sold pure or mixed with other bee products such as honey, propolis, etc. Drone brood (DB), comprising a mixture of drone larvae, is close to RJ in some physicochemical characteristics and composition but at different rates. Bee brood has nutritional value and it is increasingly used as a health food supplement. This nontraditional product can also offer a readily accessible and cheap source of biologically active substances. From chemical point of view, DB contains water (65-80\%), proteins (10-20\%), carbohydrates (10-15\%), fatty acids and lipids (4- 8\%), mineral elements (1-1.5\%), amino acids and hormones (Burmistrova, 1999; Narumi, 2004; Finke, 2005; Budnikova, 2009). Bee honey is supersaturated solution of sugars, of them 
fructose and glucose are the main contributors (Guo et al., 2011; Moussa et al., 2012). It is usually added to adulterate RJ when sugar content in the product is very low. Various methods have been identified for adulteration of RJ most frequently by mixing it with DB. Garcia-Amoedo and Almeida-Muradian (2007) have analyzed the physicochemical profile of the RJ adulterated in different proportions by the following adulterants: natural yogurt, pure water, starch corn slurry, a mixture of sweet condensed milk with propolis and unripe banana. Proper identification of both important products RJ and DB requires complete analysis and determination of major compounds. The aim of the present paper is to characterize the sugar composition of RJ samples adulterated with DB and honey in order to find out possible descriptors for adulterated RJ samples. The data presented in this paper are essential not only from scientific point of view, but it is also important for practical purposes in order easily and efficiently to assess the authenticity of RJ.

\section{Materials and Methods}

Seven RJ samples, seven DB samples and mixtures of them were analyzed. All samples were collected from experimental apiary of the Institute of Animal Science - Kostinbrod during the period May - August 2014 and were stored at $-20^{\circ} \mathrm{C}$ until the analysis.

Preparation of the adulterated RJ samples: 12 - 14-day-old drone brood (DB) larvae were taken from the DB cells and were immediately smashed. Mixtures of DB larvae were filtrated and added to the RJ samples in a proportion of 3:1 (w/w). Also, honey was added to another RJ samples in the same proportion. The samples were shaken to obtain homogeneous solutions. The adulterations with $\mathrm{DB}$ and honey were prepared in the Bee products laboratory (Institute of Animal Science -
Kostinbrod) and the samples were kept in the freezer at $-20{ }^{\circ} \mathrm{C}$ until the moment of the analysis. The sugars (fructose, glucose, sucrose) are analysed by HPLC as proposed by Sesta (2006) at Regional Food Safety Directorate - Sofia, Bulgarian Food Safety Agency (BFSA). Data were statistically processed by Student's t-test for the differences between RJ and DB samples. Means and standards deviations of means were determined with descriptive statistical methods. The differences between means at the $0.5 \% \quad(p<0.05)$ level were considered significant. Cluster analysis is applied as a method for finding different classes and groups within the obtained data. The obtained results were processed with STATISTICA 10.

\section{Results and Discussion}

As can be seen from the results significant differences were observed between the content of fructose, glucose and sucrose in RJ and DB samples. The average values and ranges for sugar content in RJ, DB samples and mixtures of RJ with $\mathrm{DB}$ and honey are presented in Table 1.

The most abundant sugar in RJ is fructose. It is almost five times higher in RJ samples compare to DB samples. The mixtures RJ+DB show high average level of fructose and this value is close to this for pure RJ samples. In this case, this parameter can not be used to distinguish one product from another.For the all analyzed samples the highest average fructose content is in the mixtures $\mathrm{RJ}+\mathrm{H}$ (Table 1). It is expected because honey contains approximately $30 \%$ fructose.

In pure RJ samples the glucose content is lower that the fructose content. The higher glucose content is specific for DB (Burmistrova, 1999) and this parameter is appropriate for identification purposes $(\mathrm{p}<0.001)$. 
Fig.1 Dendrogram from cluster analysis of RJ (n=7), DB (n=7), RJ+DB (n=7), and RJ+H ( $n=7)$ for fructose (A), glucose (B) and sucrose (C)

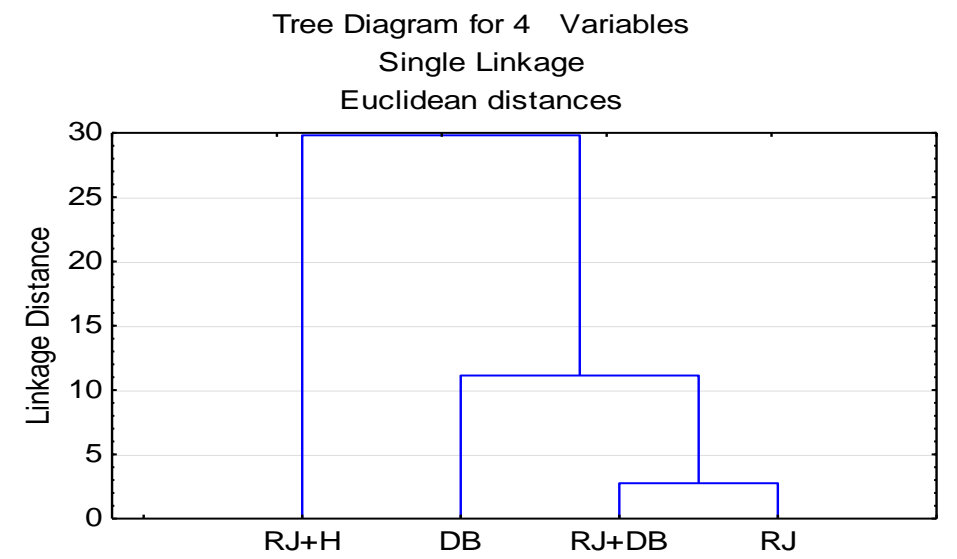

A) Fructose

Tree Diagram for 4 Variables

Single Linkage

Euclidean distances

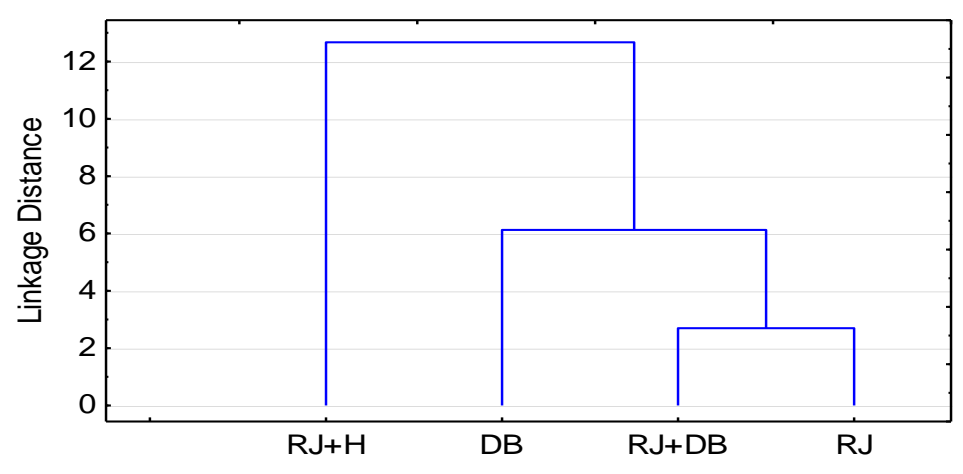

B) Glucose

Tree Diagram for 4 Variables

Single Linkage

Euclidean distances

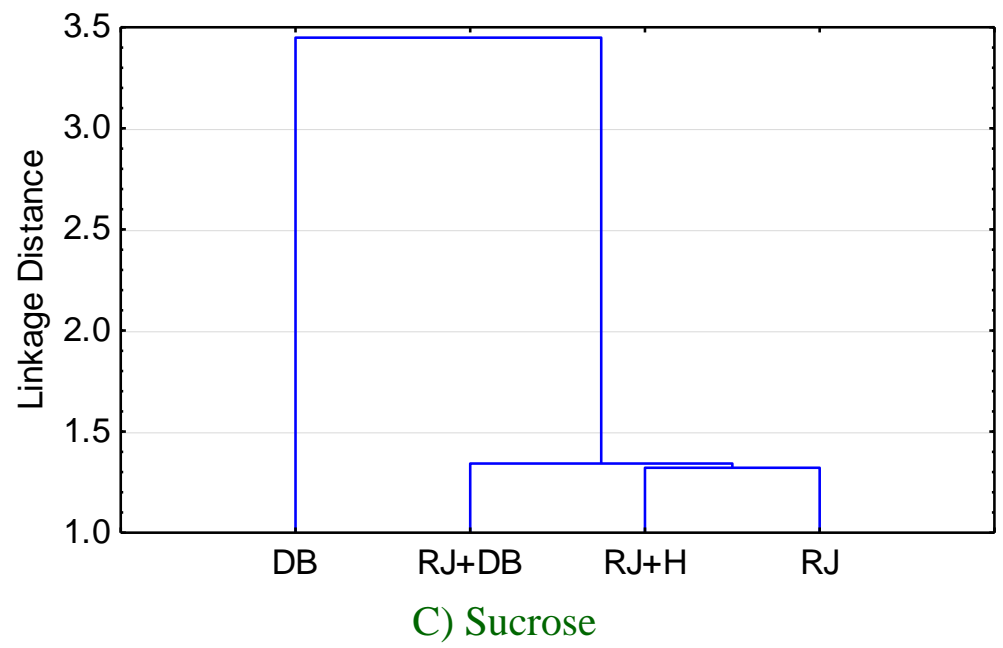


Fig.2 Dendrogram from cluster analysis of RJ (n=7), DB (n=7), RJ+DB ( $n=7)$, and RJ+H ( $n=7)$ for all parameters

Tree Diagram for 11 Variables

Single Linkage

Euclidean distances

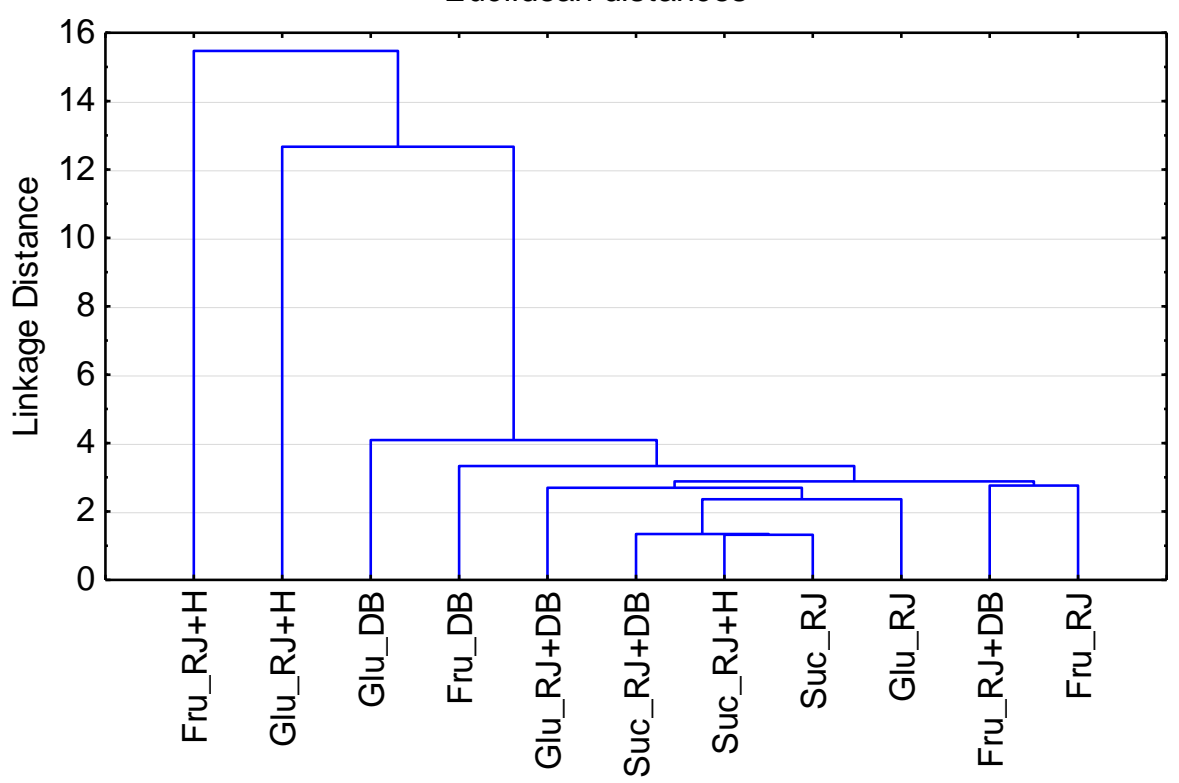

Legend: Fru - fructose; Glu - glucose; Suc - sucrose

Table.1 Main sugars in RJ and DB samples and mixtures of RJ with DB and honey $(\mathrm{H})$ in proportion $3: 1,(\mathrm{X} \pm \mathrm{SD}$ and ranges $)$

\begin{tabular}{|c|c|c|c|}
\hline & Fructose, \% & Glucose, \% & Sucrose, \% \\
\hline $\begin{array}{l}\text { Pure RJ } \\
(\mathrm{n}=7),(\min -\max )\end{array}$ & $\begin{array}{l}5.02 * * * \pm 0.75 \\
(3.96-5.88)\end{array}$ & $\begin{array}{l}2.89 \pm 0.19 \\
(2.70-3.18)\end{array}$ & $\begin{array}{l}1.89 * * * * \pm 0.30 \\
1.57-2.29 \\
\end{array}$ \\
\hline $\begin{array}{l}\text { Pure DB } \\
(\mathrm{n}=7),(\min -\max )\end{array}$ & $\begin{array}{l}0.09 \pm 0.05 \\
(0.01-0.16)\end{array}$ & $\begin{array}{l}6.92 * * * \pm 0.87 \\
(5.61-8.23)\end{array}$ & $\begin{array}{l}0.05 \pm 0.04 \\
(0.00-0.10)\end{array}$ \\
\hline $\begin{array}{l}\text { RJ+DB } \\
(n=7),(\min -\max )\end{array}$ & $\begin{array}{l}6.26 \pm 1.30 \\
4.88-8.22\end{array}$ & $\begin{array}{l}4.27 \pm 0.58 \\
3.57-5.31\end{array}$ & $\begin{array}{l}1.94 \pm 0.54 \\
1.23-2.80\end{array}$ \\
\hline $\begin{array}{l}\text { RJ+H } \\
(\mathbf{n}=7),(\min -\max )\end{array}$ & $\begin{array}{l}19.49 \pm 1.08 \\
18.19-20.96\end{array}$ & $\begin{array}{l}12.51 \pm 0.64 \\
11.59-13.44\end{array}$ & $\begin{array}{l}1.44 \pm 0.41 \\
0.90-2.01\end{array}$ \\
\hline
\end{tabular}

Note: ***Significant differences at $\mathrm{p}<0.001$ between pure RJ and DB.

This compound could be used as a very good descriptor. This is confirmed by the fact that glucose content in $\mathrm{RJ}+\mathrm{DB}$ is almost 1.5 times higher than in the pure RJ.

Sucrose content in RJ samples is relatively higher than this in DB however the values are considerably low and not enough informative
(Table 1). Results obtained for DB in this study are close to the results of Burmistrova (1999). The author reported that the proportions of the major sugars in DB are glucose $(3.16-5.00 \%)$, fructose $(0.03-0.50 \%)$ and sucrose $(0.03-0.50 \%)$. In general, sugars represent the second major fraction of compounds in $\mathrm{RJ}$ and $\mathrm{DB}$ - as a rule the 
monosaccharides fructose and glucose are the most abundant, while small amounts of disaccharides (mainly maltose and sucrose) are also presented (Balkanska, 2014). Other oligosaccharides (erlose, trehalose, maltose, isomaltose, raffinose), could be found in very small quantities in RJ (Sesta, 2006; Sabatini et al., 2009; Daniele and Casabianca, 2012). Similarly, for the honey fructose and glucose are the main ingredients. Moreover, honey contents small amount of disaccharides and trisaccharides (Guo et al., 2011; Moussa et $a l ., 2012)$. For this reason the fructose and glucose could be used for identification of adulterated RJ samples.

The results for sugar composition have gone through a statistical analysis by cluster analysis. It indicates the linkage between the clustered objects with respect to their similarity (distance measure) and takes into account majority of parameters defined for RJ identification. On Figure 1 the dendrogram for linkage of all analysed sugars are presented.The hierarchical dendrogram is shown on Figure 1 (A, B, C).For fructose and glucose the mixtures $\mathrm{RJ}+\mathrm{H}$ are outliers. For sucrose the outlier is pure drone brood (DB). It could be concluded from the cluster analysis results that parameters such as fructose, glucose and sucrose content are responsible for the relative separation of the sampling events. However, this information could be convincing enough to make decisions for identification and prediction for RJ authenticity.

On Figure 2 the hierarchical dendrogram for linkage of all analyzed samples is presented.

The results of cluster analysis (Fig. 2) confirm the results from individual dendrograms of the sugars. Again fructose and glucose in the mixtures $\mathrm{RJ}+\mathrm{H}$ are outliers. They can be used as very good descriptors for identification of RJ adulterated with honey.
The differences in fructose, glucose and sucrose content between RJ and DB samples are significant $(\mathrm{p}<0.001)$. The addition of DB and honey in RJ would change in a certain direction the composition on RJ, mainly with changes of sugar ranges of the samples. The cluster analysis turned out to be useful for finding similarity (or dissimilarity) between pure RJ and mixtures with drone brood and honey. Parameters such as fructose and glucose can be used as good descriptors for the evaluation of RJ authenticity with honey.

\section{References}

Balkanska, R. 2014. A study of the composition and physicochemical properties of fresh and lyophilized royal jelly depending on the feeding of the bee colonies and the region of the production of royal jelly. Ph.D. Thesis, Institute of Animal Science, Kostinbrod, Bulgaria.

Budnikova, N. 2009. Biologically active compounds in drone brood. Pcelovodstvo, 6, 54-56.

Burmistrova, L. 1999. Physicochemical analysis and biochemical appreciation of drone brood. Ph.D. Thesis, Ryazan Medical University, Ryazan, Russia.

Daniele, G. and Casabianca, H. 2012. Sugar composition of French royal jelly for comparison with commercial and artificial sugar samples. Food Chem. 134(2): 1025-1029.

Finke, M. 2005. Nutrient composition of bee brood and its potential as human food. Ecol. Food Nutr. 44(4): 257-270.

Garcia-Amoedo, L.H. and AlmeidaMuradian,L.B. 2007. Physicochemical composition of pure and adulterated royal jelly. Quim. Nova 30(2): 257-259.

Guo, W., Y. Liu, X. Zhu and Wang, S. 2011. Dielectric properties of honey adulterated with sucrose syrup. J. Food Eng. 107(1): 1-7. 
Moussa, A., D. Noureddine, A. Saad and Douichene, S. 2012. The relationship between fructose, glucose and maltose content with diastase number and antipseudomonal activity of natural honey combined with potato starch. Organic Chemistry: Current Research 1(5): 1-5.

Narumi, S. 2004. Honeybee brood as a nutritional food. Honeybee Science Tamagawa University 25(3): 119-124.

Sabatini, A.G., G. Marcazzan, M.F. Caboni, S. Bogdanov and Almeida-Muradian, L.B. 2009. Quality and standardisation of royal jelly. JAAS 1: 1-6.

Sesta, G. 2006. Determination of sugars in royal jelly by HPLC. Apidologie 37: 84-90.

Wytrychowski, M., S. Chenavas, G. Daniele, H. Casabianca, M. Batteau, S. Guibert and Brion, B. 2013. Physicochemical characterisation of French royal jelly: Comparison with commercial royal jellies and royal jellies produced through artificial bee-feeding. J. Food Compos. Anal. 29: 126-133.

\section{How to cite this article:}

Ralitsa Balkanska. 2018. Sugar Composition of Royal Jelly Adulterated with Drone Brood and Bee Honey. Int.J.Curr.Microbiol.App.Sci. 7(02): 1876-1881.

doi: https://doi.org/10.20546/ijcmas.2018.702.226 